\title{
Crustáceos decápodos associados aos bancos de Phragmatopoma caudata (Kröyer) (Polychaeta, Sabellariidae) na Praia de Caiobá, Matinhos, Paraná ${ }^{1}$
}

\author{
Cláudia Regina Bosa ${ }^{2}$ \\ Setuko Masunari ${ }^{3}$
}

\begin{abstract}
Decapod crustaceans associated to worm reefs of Phragmatopoma caudata (Kröyer) (Polychaeta, Sabellariidae) from Caiobá beach, Matinhos, Paraná. A study about species composition, relative abundance, densities, size composition, reproductive and recruiting periods, sex proportion and species diversity of the decapod populations associated to worm reefs of $P$. caudata (Kröyer, 1856) was carried out. Monthly, samples of worm reef were obtained from August/1997 to

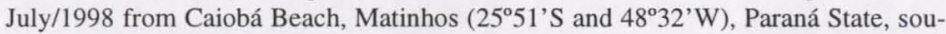
thern Brazil. Air temperature oscillated from $14.5^{\circ} \mathrm{C}$ (July) to $31.0^{\circ} \mathrm{C}$ (February), surface water from $18.0^{\circ} \mathrm{C}$ (July) to $28.0^{\circ} \mathrm{C}$ (January and February), and the salinity from 22\%o (February) to 34\%o (September). Eigth decapod species were found: Petrolisthes armatus (Gibbes, 1850); Pachygrapsus transversus (Gibbes, 1850); Panopeus americanus Saussure, 1857; Eurypanopeus abbreviatus (Stimpson, 1860); Menippe nodifrons Stimpson, 1859; Pilumnus dasypodus Kingsley, 1879; Eriphia gonagra (Fabricius, 1781); and Alpheus heterochaelis Say, 1818. The total density varied from 1.66 ind./I (September) to 33.93 ind./I (January). Petrolisthes armatus was the most numerous species. Six species were constant, one was accessory, and another accidental. Shannon-Wiener diversity index was the lowest when compared with other similar habitats. Ovigerous females occurred in six species, but no species showed continuous breeding all year round. The majority of the associated decapods were smaller than those reported in the literature.
\end{abstract}

KEY WORDS. Decapod crustacean, association, Phragmatopoma, Caiobá

O poliqueto sabelariídeo Phragmatopoma lapidosa Kinberg, 1867, hoje Phragmatopoma caudata (Kröyer, 1856), tem uma larga distribuição nas Américas, primariamente em águas marinhas tropicais, ocorrendo desde o Cabo Canaveral nos E.U.A. até o Estado de Santa Catarina (FANTA 1968). Como outros membros da mesma família, a espécie tem uma habilidade peculiar de formar extensos bancos de areia, freqüentemente chamados de "recifes", nas zonas de arrebentação das ondas, principalmente em ambientes expostos ao mar aberto. Estes poliquetos utilizam partículas de areia e um cimento muco-protêico para elaborar seus tubos de habitação, os quais coalescem formando grandes colônias à medida que o desenvolvimento e o assentamento têm continuidade (GORE et al. 1978). Fatores

1) Contribuição número 1261 do Departamento de Zoologia, Universidade Federal do Paraná.

2) Departamento de Patologia Básica, Universidade Federal do Paraná.

3) Departamento de Zoologia, Universidade Federal do Paraná. Caixa Postal 19020, 81531-980 Curitiba, Paraná, Brasil. E-mail: setmas@bio.ufpr.br 
relacionados à biologia do animal como compostos bioadesivos (GRUET et al. 1987; JENSEN \& MORSE 1988) ou bioativos (PAWLIK 1990) atuam de forma decisiva no processo de colonização de substratos. Além disso, certas características abióticas como agitação da água (TAYLOR \& LITTLER 1982; LITTLER et al. 1983) e composição granulométrica da areia (MAIN \& NELSON 1988a,b) atuam como elementos reguladores no desenvolvimento destes bancos. Estes, freqüentemente oferecem refúgios estruturais para os organismos infaunais (WILSON 1979).

Parte dos trabalhos sobre $P$. caudata versa sobre aspectos geológicos ou de sistemática (ver revisão em GORE et al. 1978). Aspectos ecológicos foram tratados pioneiramente por autores brasileiros: NARCHI \& RODRIGUES (1965), FANTA (1968) e FAUSTO-FILHO \& FURTADO (1970). Mais recentemente, no país, a fauna de decápodos associados aos bancos deste poliqueto foi tratada por PINHEIRO et al. (1997) no litoral norte do Estado de São Paulo, e a fauna de decápodos porcelanídeos por MiCHELETTI-FLORES \& NEGREIROS-FRANSOZO (1999).

Nos países estrangeiros, autores variados trataram da descrição da fauna associada aos bancos de poliquetos tubícolas coloniais dos gêneros Sabellaria Lamarck, 1812, Phragmatopoma Mörch, 1863, Owenia Chiaje, 1841 e Polydora Bosc, 1802 (ver revisão em WILSON 1979). Um trabalho extenso sobre a fauna associada a $P$. caudata foi realizado por GoRE et al. (1978), em bancos do litoral da Flórida, E.U.A. O resultado de dois anos de coleta mostrou que os mesmos abrigam uma fauna diversificada e abundante, totalizando 96 espécies dentre os Stomatopoda e Decapoda (Crustacea). No mesmo ambiente, outros grupos de Crustacea como os Peracarida (Amphipoda e Isopoda), também foram expressivos, somando 11 espécies (NELSON \& DEMETRIADES 1992).

Mais recentemente, PORRAS et al. (1996) analisaram a estrutura trófica de poliquetos associados aos recifes do sabelariídeo Sabellaria alveolata (Linnaeus, 1767), registrando 22 espécies e quatro guildas tróficas compreendidas por carnívoros, consumidores de depósitos de subsuperfície, consumidores de depósitos de superfície e suspensívoros. Observaram ainda uma relação direta entre o crescimento destes recifes e a organização dos grupos de poliquetos associados: no início há dominância de $S$. alveolata, porém, no final há um aumento de riqueza de espécies destes animais. Outros exemplos de coexistência de espécies ecologicamente similares foram tratados por FENCHEL et al. (1975), GORE et al. (1978) e WHITLATCH (1980).

O presente trabalho propõe um estudo descritivo das populações de decápodos associados aos bancos de P. caudata da Praia de Caiobá, Paraná, enfocando os seguintes aspectos: composição e constância das espécies, flutuação anual de densidade, composição de tamanho dos indivíduos, período reprodutivo e de recrutamento nas populações, proporção de sexos e diversidade de espécies.

\section{MATERIAL E MÉTODOS}

A Praia de Caiobá constitui um dos raros afloramentos rochosos do Estado do Paraná (Bigarella 1978). Entre a Ponta de Caiobá (2551'S e $48^{\circ} 32^{\prime} \mathrm{W}$ ) e a Ilha do Farol, há um caminho de matacões, seixos e cascalhos assentados sobre um substrato arenoso (ver mapa em MASUNARI et al. 1998), nos quais animais sésseis 
e algas colonizam sua superfície. Localizado na faixa do mediolitoral, o referido caminho de matacões fica totalmente emerso durante as marés vazantes de sizígia.

Os bancos de $P$. caudata ocorrem na forma de uma faixa bem definida de $40-50 \mathrm{~cm}$ de largura no nível mediano do mediolitoral, formando um cinturão contínuo desde a Ponta de Caiobá até a face nordeste da Ilha do Farol, incluindo o caminho de matacões que liga a ilha ao continente.

As marés no litoral do Paraná são do tipo semi-diurno, e a média anual é de 0,84 m no Canal da Galheta, local com marégrafo mais próximo da Praia Caiobá. A amplitude de oscilação chega a $2 \mathrm{~m}$ em condições extremas (DNH 1997, 1998).

As coletas foram realizadas, mensalmente, de agosto/1997 a julho/1998, durante as marés vazantes de sizígia. Temperaturas do ar e da água de superfície foram tomadas com um termômetro de mercúrio comum e a salinidade com um refratômetro Shibuya S-28. As condições climáticas por ocasião da coleta também foram registradas. Três amostras de colônia de $P$. caudata foram coletadas a cada mês. Devido ao crescimento irregular dos bancos da colônia, cada amostra consistiu de um bloco de aproximadamente $30 \mathrm{~cm}$ de lado, que foi retirado com o auxílio de uma talhadeira e um martelo. Após a retirada do bloco, este foi mergulhado em uma balde graduado contendo volume conhecido de água e, por deslocamento de líquido, o volume da amostra foi obtido. A amostra foi retirada do líquido, colocada em saco plástico e levada ao laboratório. Em seguida, os talos da alga Ulva spp. foram recolhidos e o bloco foi fragmentado até o tamanho de areia, durante o qual, os animais de maior porte foram coletados manualmente. A areia que ficou depositada no fundo da bandeja foi lavada pelo menos três vezes, sendo a água com o sobrenadante passada em uma peneira de $1 \mathrm{~mm}$ de abertura de malha, a fim de recolher os animais menores. Os decápodos obtidos foram fixados em formalina glicerinada e conservados em álcool 70\% glicerinado. Após, foram identificados, contados e discriminados quanto ao sexo e ao estágio de desenvolvimento (megalopa, juvenil, macho, fêmea sem ovos e fêmea ovígera). A largura da carapaça foi mensurada com auxílio de paquímetro e microscópio estereoscópico equipado com ocular graduada.

A densidade foi calculada em número de indivíduos por volume de amostra em litros. A proporção de sexos das espécies mais abundantes foi calculada mensalmente com base na freqüência relativa dos mesmos, desconsiderando-se os exemplares juvenis. Diferenças significativas foram calculadas com o $\mathrm{X}^{2}$ (Quiquadrado) num nível de significância de 5\%.

De acordo com a frequiência de ocorrência nas amostras (F.O.), as espécies foram classificadas segundo DAJOZ (1973) em constante (F.O. em mais de 50\% das amostras), acessória $(25 \%<$ F.O. $<50 \%$ ) ou acidental (F.O. $<25 \%)$.

As classes de largura da carapaça estabelecidas para cada espécie tiveram intervalos variados, de acordo com a amplitude de seu tamanho.

O período reprodutivo foi inferido com base na frequiência relativa mensal de fêmeas ovígeras em relação ao total de fêmeas adultas, ao passo que, o período de recrutamento dos decápodos mais abundantes, nas freqüências relativas mensais de juvenis em relação à população total amostrada. 
A diversidade de espécies foi expressa segundo o índice de Shannon-Wiener (H') (KREBS 1994), com base binária e o resultado expresso em bits/indivíduo. Uma comparação com os índices disponíveis na literatura para outros habitats foi realizada.

\section{RESULTADOS}

A altura da maré mínima prevista para a Barra do Porto de Paranaguá, Canal da Galheta, Paraná, nos dias de coleta variou de $0,0 \mathrm{~m}$ (agosto e setembro) a $0,6 \mathrm{~m}$ (janeiro); a temperatura do ar, de $14,5^{\circ} \mathrm{C}$ (julho) a $31,0^{\circ} \mathrm{C}$ (fevereiro) e a temperatura da água de superfície, de $18,0^{\circ} \mathrm{C}$ (julho) a $28,0^{\circ} \mathrm{C}$ (janeiro e fevereiro) (Fig. 1A). De um modo geral, os meses do final de outono e inverno foram mais frios, quando as temperaturas do ar e da água de superfície não ultrapassaram os $22^{\circ} \mathrm{C}$. Por outro lado, nos meses de fim da primavera, verão e início do outono, elas foram sempre superiores ou iguais a $22^{\circ} \mathrm{C}$. Fevereiro foi o mês mais quente. $\mathrm{Na}$ maioria dos meses de coleta, a temperatura da água de superfície se mostrou mais estável que a do ar, sendo mais alta em agosto, outubro, dezembro, fevereiro e abril.

A salinidade da água de superfície variou de $22,0 \%$ (fevereiro) a $34,0 \%$ o (setembro) (Fig. 1A). O tempo por ocasião da coleta foi bom com sol em cinco dos doze meses de coleta (agosto/1997, setembro/1997, dezembro/1997, maio/ 1998 e julho/1998), nublado em cinco meses (novembro/1997, janeiro/1998, fevereiro/1998, abril/1998, junho/1998), com chuvisco em um mês (março/1998) e chuvoso em um mês (outubro/1997).

A amplitude de variação da densidade total de decápodos foi de 1,66 ind./l (setembro) a 33,93 ind./l (janeiro) (Fig. 1B). Houve maior densidade em janeiro, fortemente influenciada pela população de Petrolisthes armatus (Gibbes, 1850). Em fevereiro houve influência da população de Panopeus americanus Saussure, 1857. Em ambos os casos, os altos valores estão relacionados à entrada de indivíduos juvenis na população dessas espécies.

\section{Composição e constância das espécies}

Foram coletados 1769 indivíduos de oito espécies, distribuídos em quatro famílias: Porcellanidae (1 espécie): Petrolisthes armatus (909 indivíduos); Xanthidae (5espécies): Panopeus americanus (363), Eurypanopeus abbreviatus (Stimpson, 1860) (56), Menippe nodifrons Stimpson, 1859 (53), Pilumnus dasypodus Kingsley, 1879 (22) e Eriphia gonagra (Fabricius, 1781) (4); Grapsidae (1 espécie): Pachygrapsus transversus (Gibbes, 1850) (288); e Alpheidae (1 espécie): Alpheus heterochaelis Say, 1818 (74).

Das oito espécies, seis foram constantes: Petrolisthes armatus (freqüência de ocorrência em $100 \%$ das amostras), Pachygrapsus transversus (100\%), Alpheus heterochaelis (75\%), Panopeus americanus (75\%), Eurypanopeus abbreviatus $(58,33 \%)$ e Menippe nodifrons $(58,33 \%)$. Houve apenas uma espécie acessória Pilumnus dasypodus $(41,66 \%)$ e uma espécie acidental - Eriphia gonagra $(16,66 \%)$. 

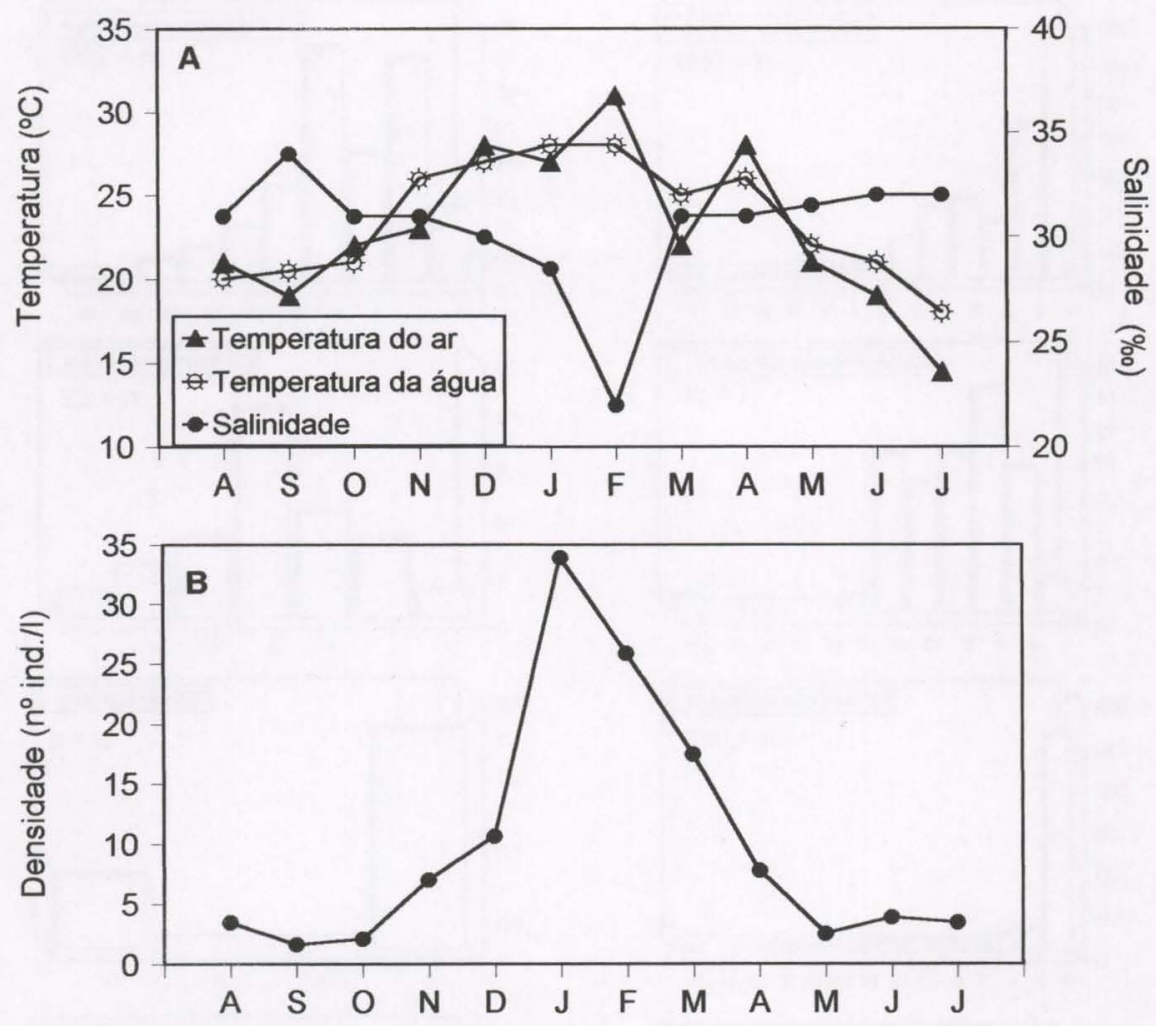

Fig. 1. (A) Flutuação anual da temperatura do ar, da água de superfície e salinidade; (B) flutuação anual da densidade total ( $n^{\circ}$ ind..$\left.^{-1}\right)$ de decápodos registrados durante o período de agosto/1997 a julho/1998.

\section{Distribuição da freqüência absoluta}

A figura 2 mostra a distribuição da freqüência absoluta das espécies de decápodos associados aos bancos de $P$. caudata. Na maioria das espécies registradas foi verificada uma maior freqüência de indivíduos nas classes de menor largura ou comprimento da carapaça, ocorrendo um deslocamento da curva de distribuição normal para a esquerda, exceto para Pilumnus dasypodus, onde foi observado um maior número de indivíduos nas classes de largura da carapaça com valores intermediários.

\section{Flutuação anual de densidade das espécies}

Porcellanidae. Petrolisthes armatus foi registrado em todos os meses de coleta, tendo sido encontrado em todos os estágios de desenvolvimento. A maior densidade ocorreu em janeiro (30,51 ind./l), devido à entrada de megalopas na população. A segunda maior densidade, foi registrada em março (10,08 ind./l). Este decápodo foi o mais abundante do presente estudo (Fig. 3). 

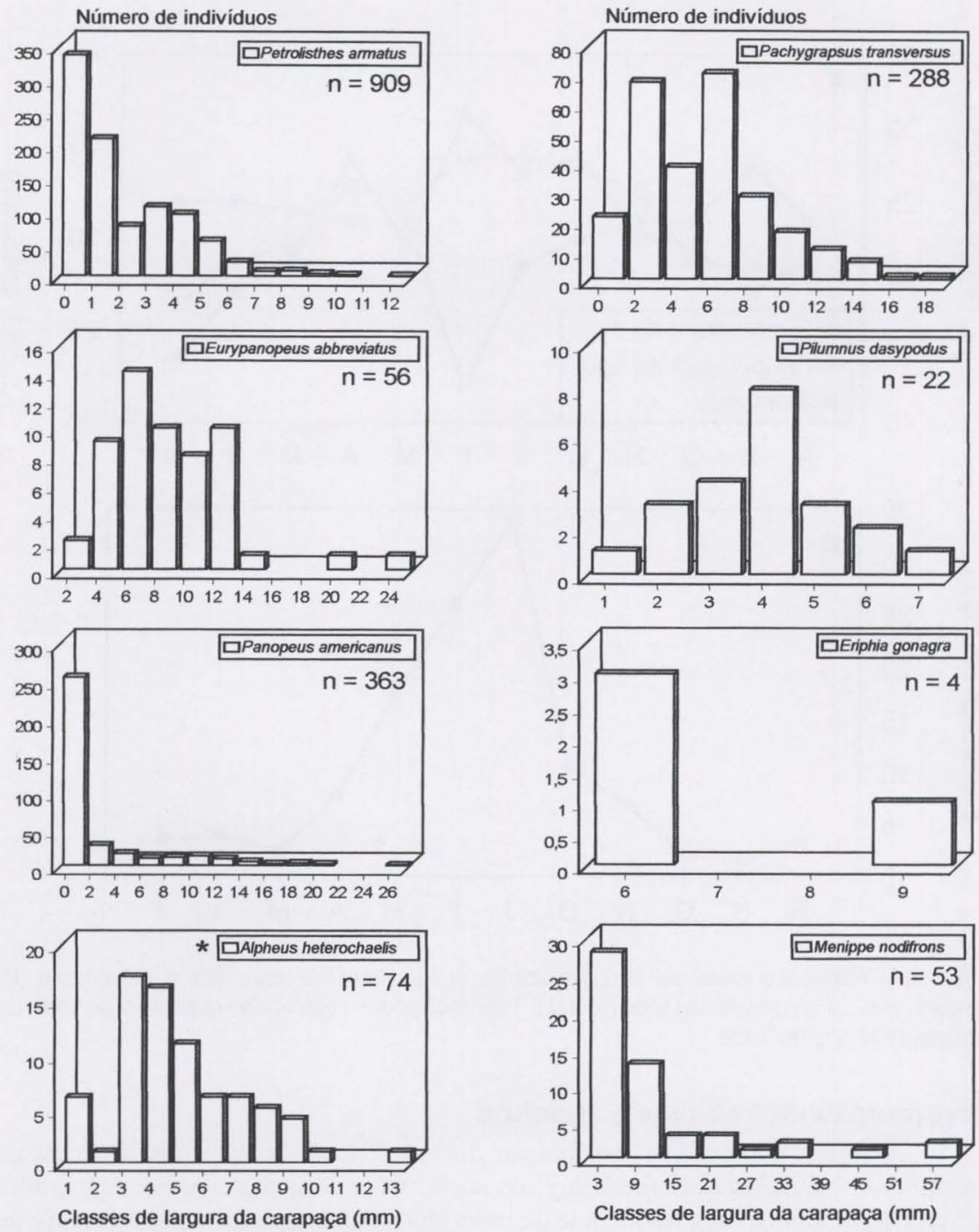

Fig. 2. Decápodos associados aos bancos de Phragmatopoma caudata. Distribuição da freqüência absoluta total das espécies de decápodos registradas nas classes de largura da carapaça $(\mathrm{mm})$. Observe que o intervalo de classes nas diferentes espécies é variado. $\left(^{*}\right)$ Classes de comprimento da carapaça.

Xanthidae. Panopeus americanus ocorreu em nove dos doze meses de coleta e com exceção do estágio megalopa ocorreu em todos os estágios de desenvolvimento. Foi o segundo decápodo mais abundante do presente estudo. A maior densidade foi registrada em fevereiro (15,22 ind./l) devido à entrada de indivíduos juvenis na população. Menippe nodifrons foi registrado em sete meses de coleta, somente como machos ou fêmeas, com maiores densidades em abril $(2,08$ 

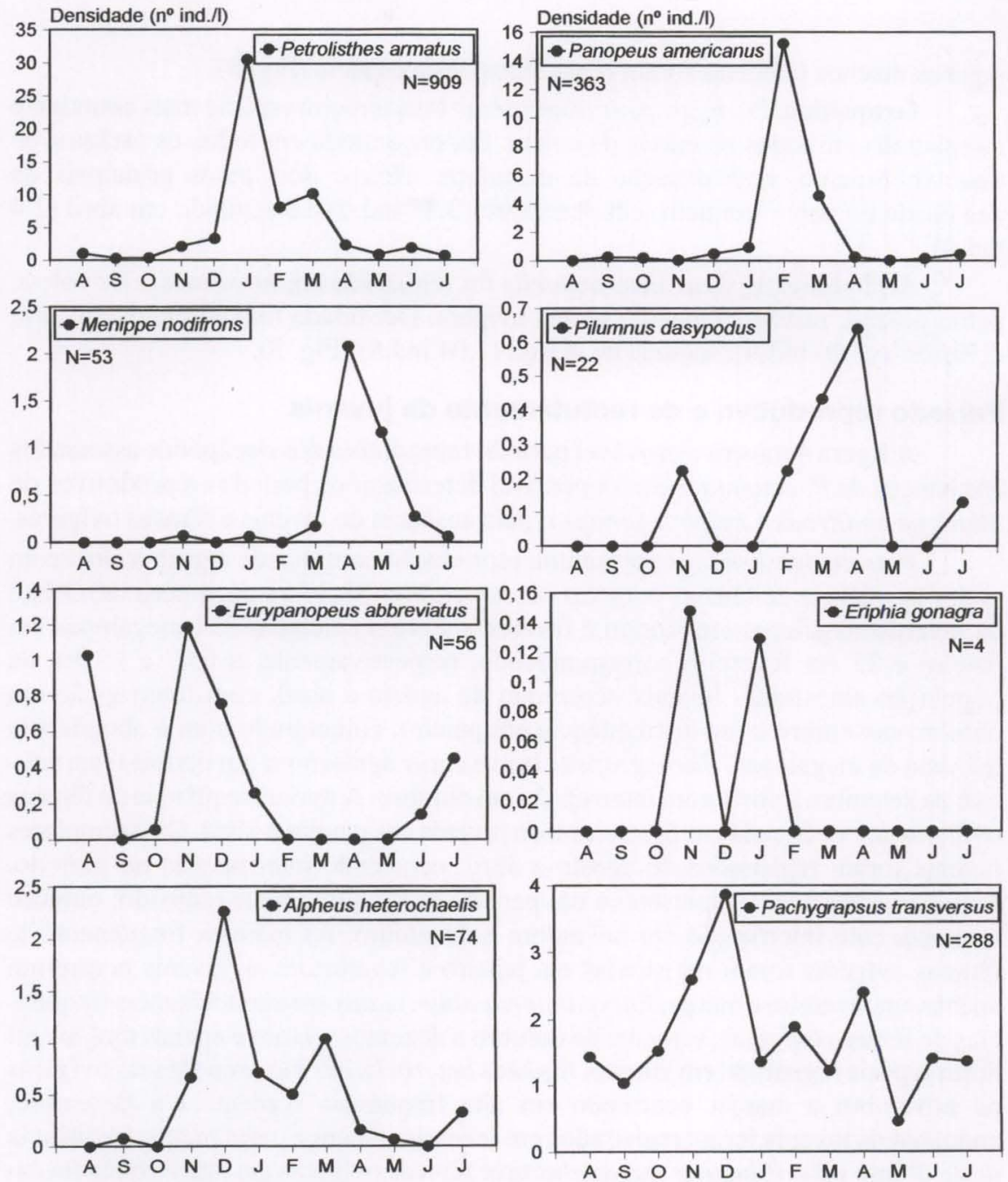

Fig. 3. Decápodos associados aos bancos de Phragmatopoma caudata. Flutuação anual de densidade $\left(\mathrm{n}^{\circ}\right.$ ind. $\mathrm{I}^{-1}$ ) das espécies registradas no período de agosto/1997 a julho/1998. Observe que a escala de densidade é variada.

ind./l) e maio (1,16 ind./l). Com exceção de megalopa, Pilumnus dasypodus ocorreu em todos os estágios de desenvolvimento, em densidades baixas e apenas em cinco meses de coleta. A maior densidade ocorreu em abril (0,64 ind./l). Eurypanopeus abbreviatus foi registrado em sete meses de coleta, havendo apenas um exemplar juvenil, sendo os demais, machos, fêmeas e fêmeas ovígeras. Os meses em que ocorreram as maiores densidades foram: agosto (1,02 ind./l) e novembro $(1,18$ ind./l); neste último mês foi registrado a maior densidade. Eriphia gonagra ocorreu em densidades baixas e somente em novembro $(0,14$ ind./l)e em janeiro $(0,12$ ind./l). 
Apenas machos e fêmeas foram registrados desta espécie (Fig. 3).

Grapsidae. Pachygrapsus transversus foi a terceira espécie mais abundante e registrada em todos os meses de coleta. Foi encontrada em todos os estágios de desenvolvimento, com exceção de megalopa. Houve dois picos principais de densidade no ano: o primeiro em dezembro (3,86 ind./l) e o segundo em abril $(2,4$ ind./l).

Alpheidae. Alpheus heterochaelis foi registrado em nove meses de coleta, como juvenil, macho, fêmea ou fêmea ovígera. Densidade máxima registrada em dezembro (2,26 ind./l), seguida de março (1,04 ind./l) (Fig. 3).

\section{Período reprodutivo e de recrutamento de juvenis}

A figura 4 mostra o provável período reprodutivo dos decápodos associados aos bancos de $P$. caudata. Não foi possível determinar os períodos reprodutivos de Menippe nodifrons e Eriphia gonagra, pela ausência de juvenis e fêmeas ovígeras.

Petrolisthes armatus apresentou reprodução contínua de agosto a abril com maior freqüência de fêmeas ovígeras em novembro $(88,2 \%)$ e dezembro $(83,3 \%)$ e de juvenis/megalopas em janeiro e fevereiro. Foram coletadas 311 megalopas em janeiro e 23 em fevereiro correspondendo, respectivamente, a 65,7 e $15,8 \%$ da população amostrada. Juvenis ocorreram de agosto a abril, com interrupção em outubro-novembro e maior freqüência em janeiro, coincidindo com a abundância máxima de megalopas. Pachygrapsus transversus apresentou um período reprodutivo de setembro a abril, com interrupção em outubro. A maior freqüência de fêmeas ovígeras foi verificada em fevereiro e de juvenis em janeiro e abril. Os exemplares juvenis foram registrados de agosto a abril, ocorrendo interrupções no período. Panopeus americanus apresentou um período reprodutivo mais reduzido: outubro a março, com interrupção em novembro e dezembro. As maiores freqüências de fêmeas ovígeras foram registradas em janeiro e fevereiro e os juvenis ocorreram apenas em fevereiro e março. Eurypanopeus abbreviatus apresentou baixas freqüências de fêmeas ovígeras, somente de outubro a dezembro. Houve apenas um juvenil desta espécie registrado em janeiro. Alpheus heterochaelis mostrou fêmeas ovígeras de novembro a março, ocorrendo em alta freqüência somente em dezembro, enquanto os juvenis foram registrados em fevereiro e março, com menor freqüência neste último mês. Pilumnus dasypodus teve fêmeas ovígeras em alta freqüência em fevereiro e menor freqüência em novembro e março. Os juvenis ocorreram apenas no mês de abril (Fig. 4).

\section{Proporção mensal de sexos}

A figura 5 apresenta a freqüência relativa mensal dos machos das três espécies de decápodos mais numerosas associadas aos bancos de $P$. caudata. Em Petrolisthes armatus houve maior frequiência de fêmeas em todos os meses, mas, com diferença significativa apenas em agosto, março e abril. Em setembro ocorreram apenas fêmeas. Em Panopeus americanus não houve diferenças significativas na proporção de sexos ao longo do período de estudo ( $p>0,05)$, embora as fêmeas tenham ocorrido em maior frequiência que os machos em outubro, janeiro e fevereiro. Os machos foram mais numerosos em setembro, março, abril e julho. Em 


\begin{tabular}{|c|c|c|c|c|c|c|c|c|c|c|c|c|c|}
\hline \multicolumn{2}{|l|}{ Espécies } & \multicolumn{5}{|c|}{1997} & \multicolumn{7}{|c|}{1998} \\
\hline & & A & $\mathrm{S}$ & $\mathrm{O}$ & $\mathrm{N}$ & D & $\mathrm{J}$ & $\mathrm{F}$ & $\mathbf{M}$ & $\mathbf{A}$ & $\mathbf{M}$ & $\mathrm{J}$ & $\mathrm{J}$ \\
\hline \multirow[t]{3}{*}{ Petrolisthes armatus } & FO & $\bullet$ & & $\bullet$ & 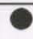 & 0 & $\bullet$ & $\bullet$ & $\bullet$ & $\bullet$ & & & \\
\hline & $\mathrm{J}$ & $\square$ & $\square$ & & & $\square$ & $\mathbf{\square}$ & $\mathbf{\square}$ & $\square$ & $\square$ & & & \\
\hline & M & & & & & & 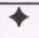 & $\diamond$ & & & & & \\
\hline \multirow[t]{2}{*}{ Pachygrapsus transversus } & FO & & $\bullet$ & & $\bullet$ & $\bullet$ & $\bullet$ & 0 & $\bullet$ & $\bullet$ & & & \\
\hline & $\mathrm{J}$ & $\square$ & $\square$ & & $\square$ & & $\mathbf{\square}$ & $\square$ & & $\square$ & & & \\
\hline \multirow[t]{2}{*}{ Panopeus americamus } & $\mathrm{FO}$ & & & $\bullet$ & & & 0 & 0 & $\bullet$ & & & & \\
\hline & $\mathrm{J}$ & & & & & & & $\square$ & $\mathbf{a}$ & & & & \\
\hline \multirow[t]{2}{*}{ Eurypanopeus abbreviatus } & FO & & & $\bullet$ & $\bullet$ & $\bullet$ & & & & & & & \\
\hline & $\mathrm{J}$ & & & & & & $\square$ & & & & & & \\
\hline \multirow[t]{2}{*}{ Alpheus heterochaelis } & $\mathrm{FO}$ & & & & $\bullet$ & O & $\bullet$ & $\bullet$ & $\bullet$ & & & & \\
\hline & $\mathrm{J}$ & & & & & & & $\square$ & $\square$ & & & & \\
\hline \multirow[t]{2}{*}{ Pilummus dasypodus } & FO & & & & $\bullet$ & & & 0 & $\bullet$ & & & & \\
\hline & $\mathrm{J}$ & & & & & & & & & $\square$ & & & \\
\hline
\end{tabular}

Freqüência alta de fềmeas ovígeras $(\mathrm{F}>50 \%)$

- Freqüência baixa de fềmeas ovígeras $(\mathrm{F}>50 \%)$

\ Freqüência alta de megalopas ( $\mathrm{F}>50 \%)$ $(\mathrm{F}<50 \%)$

FO - Fêmeas ovígeras
Frequência alta de juvenis $(\mathrm{F}<50 \%)$

$\square$ Freqüência baixa de juvenis ( $\mathrm{F}<50 \%$ )

$\diamond$ Freqüência baixa de megalopas

Fig. 4. Decápodos associados aos bancos de Phragmatopoma caudata. Prováveis períodos reprodutivos e de recrutamento das espécies. Não foram registrados juvenis ou fêmeas ovígeras de Menippe nodifrons e Eriphia gonagra.

dezembro e junho houve apenas machos. A proporção de sexos em Pachygrapsus transversus mostrou diferenças significativas somente em dezembro e março ( $\mathrm{p}<$ $0,05)$, quando o número de machos sobrepujou o de fêmeas. Os machos ultrapassaram as fêmeas numericamente, sem diferenças significativas em agosto, janeiro, junho e julho; a freqüência de fêmeas foi maior que a de machos, sem diferenças significativas, nos demais meses.

\section{Proporção de sexos nas classes de tamanho}

A figura 6 apresenta a proporção de sexos nas respectivas classes de largura da carapaça para os decápodos mais numerosos, associados aos bancos de $P$. caudata. Em Petrolisthes armatus, as fêmeas sobrepujaram os machos nas classes compreendidas entre 2 e $9 \mathrm{~mm}$, porém com diferenças significativas entre 2 a $7 \mathrm{~mm}(\mathrm{p}<0,05)$. Nas demais classes não ocorreram diferenças significativas ( $p>0,05)$. Em Panopeus americanus, na classe 4-6 mm houve diferença significativa na proporção de sexos, com os machos sobrepujando as fêmeas. Os machos foram mais freqüentes, porém sem diferença significativa, nas seguintes classes: 6-8mm; $8-10 \mathrm{~mm}$ e $18-20 \mathrm{~mm}$. Nas 

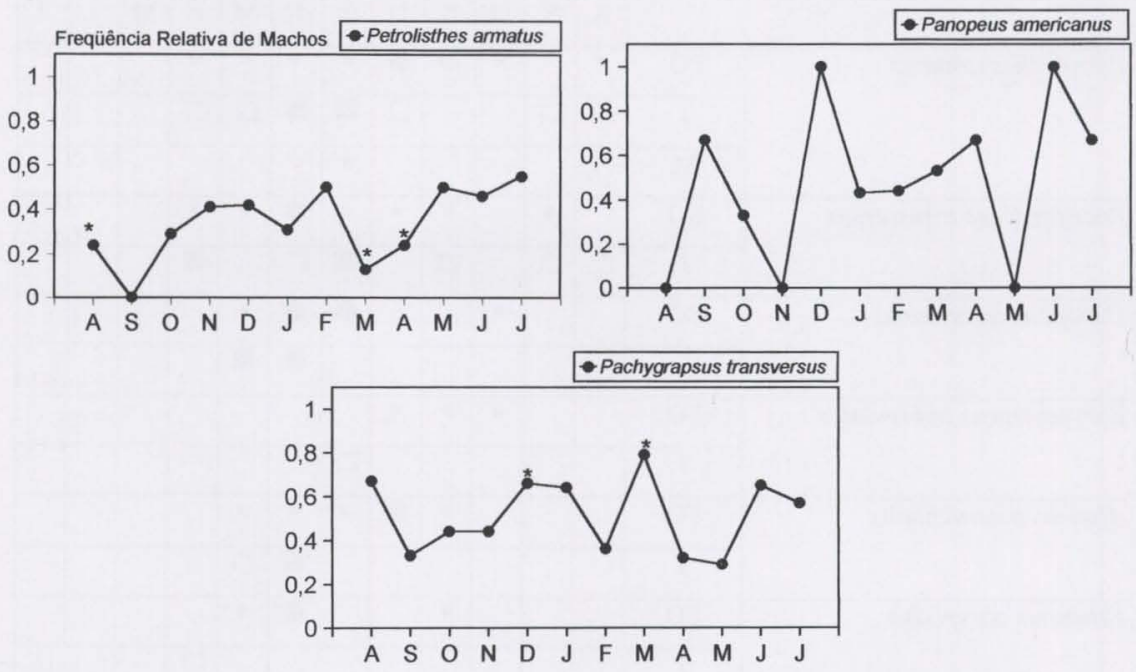

Fig. 5. Decápodos associados aos bancos de Phragmatopoma caudata. Flutuação anual da proporção de sexos, nas populações das três espécies mais numerosas. ( $\left.{ }^{\star}\right)$ Diferença significativa $(p<0,05)$.
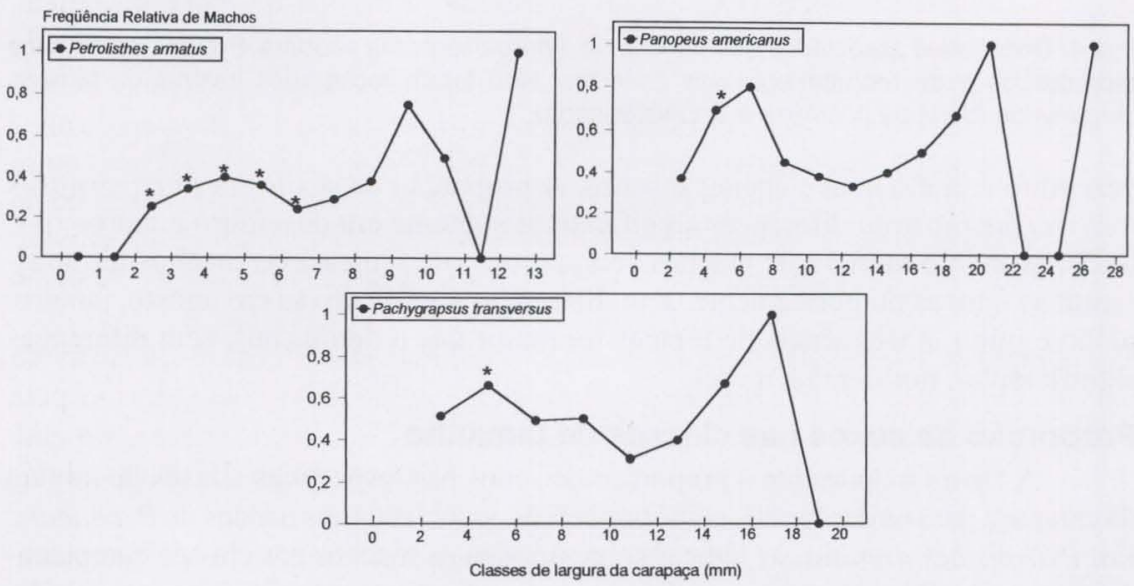

Fig. 6. Decápodos associados aos bancos de Phragmatopoma caudata. Proporção de sexos nas classes de largura da carapaça, nas populações das três espécies mais numerosas. (*) Diferença significativa $(p<0,05)$. 
classes 20-22 mm e 26-28 mm, ocorreram somente machos em baixas freqüências. Nas demais classes, as fêmeas foram mais freqüentes que os machos, sem diferenças significativas. Em Pachygrapsus transversus, ocorreu diferença significativa de machos apenas na classe 4-6 mm ( $p<0,05$ ), não ocorrendo o mesmo nas classes 2-4 mm e 14-16 mm. As fêmeas ultrapassaram a freqüência de machos sem diferenças significativas nas seguintes classes: 6-8 mm; 10-12 mm e 12-14 mm. Machos e fêmeas ocorreram na mesma proporção na classe $8-10 \mathrm{~mm}$. Na classe $16-18 \mathrm{~mm}$ foi registrado apenas um macho e na classe $18-20 \mathrm{~mm}$, apenas uma fêmea.

\section{Diversidade de espécies de decápodos}

Compondo a assembléia de decápodos associados aos bancos de $P$. caudata foram registrados 1769 indivíduos pertencentes a oito espécies (ver item Composição e Constância das Espécies). O índice de diversidade (H') obtido foi de 1,99 bits/indivíduo, com alta freqüência de Petrolisthes armatus que representou 51,38\% do total de decápodos coletados.

\section{DISCUSSÃO}

Os valores de temperatura da água de superfície e do ar registrados durante o período de coleta oscilaram num padrão de valores mais altos no verão, e valores mais baixos no inverno. OlIVEIRA \& MASUNARI (1995) mencionam que o valor mínimo de temperatura do ar que obtiveram $\left(13^{\circ} \mathrm{C}\right)$ no mesmo local, está muito abaixo da média do valor mínimo referido por MAACK (1968) para a região $\left(17^{\circ} \mathrm{C}\right)$ e que o valor máximo registrado $\left(28^{\circ} \mathrm{C}\right)$ está muito acima da média do valor do mês mais quente do ano, que foi de $24,5^{\circ} \mathrm{C}$. No presente estudo, constatou-se o mesmo, pois, o valor mínimo registrado para a temperatura do ar foi de $14,5^{\circ} \mathrm{C}$ em julho, enquanto o máximo foi de $31^{\circ} \mathrm{C}$, em fevereiro. Em sete dos doze meses de coleta, a temperatura da água de superfície foi superior à do ar, o que pode ser explicado pelo alto calor específico da água.

ECKELBARGER (1976) constatou que a temperatura ideal para o desenvolvimento das larvas de $P$. caudata está entre 24,0 e $26,0^{\circ} \mathrm{C}$ e que, em temperaturas entre 15,5 e $29,5^{\circ} \mathrm{C}$ ainda há $50 \%$ de sobrevivência. No presente estudo, a temperatura da água variou de 18,0 a $28,0^{\circ} \mathrm{C}$, apresentando-se dentro dos valores propícios ao desenvolvimento larval deste poliqueto, o que explica a ampla colonização existente na Praia de Caiobá.

Os valores de salinidade registrados confirmam a influência estuarina da Baía de Guaratuba no local de estudo, seja pelo padrão de oscilação como pela amplitude de 12 ppmil durante o período estudado. A salinidade excepcionalmente baixa registrada em fevereiro pode ser explicada pela ocorrência de intensa pluviosidade nos dias anteriores à coleta neste mês.

O pico de densidade total dos decápodos registrado em janeiro foi fortemente influenciado pela abundância de Petrolisthes armatus (compare as Figs 1B e 2), confirmando os resultados de OLIVEIRA \& MASUNARI (1995) para a mesma espécie na Ilha do Farol. Entretanto, MASUNARI et al. (1998) verificaram um pico de densidade em março, provavelmente devido ao método de coleta, que excluiu a captura de megalopas desta espécie. 
A segunda maior densidade total do presente estudo, registrada em fevereiro e influenciada pela população de Panopeus americanus, também, coincide com os dados de MASUNARI et al. (1998).

Como a maioria das espécies de decápodos registradas apresenta ocorrência constante, pode-se dizer que os bancos de $P$. caudata constituem um ambiente relativamente estável e adequado ao estabelecimento destas populações. Esta estabilidade, provavelmente, deve-se ao rápido desenvolvimento das colônias de $P$. caudata, e distúrbios causados por abrasão natural, ação humana ou impacto das ondas podem ser superados em poucos dias (ECKELBARGER 1976).

Estudando a estrutura da assembléia de decápodos associados aos recifes de corais do Panamá, ABELE (1976) e ABELE \& PATTON (1976) coletaram um total de 61 espécies, das quais 55 de decápodos, perfazendo $89 \%$ do total de espécies e $96 \%$ do total de indivíduos coletados; AUSTIN et al. (1980), em estudo semelhante, verificaram que a maioria das espécies animais associadas é rara e que os crustáceos, especialmente os decápodos são os dominantes. GORE et al. (1978) verificaram que 96 espécies de decápodos dominam a macrofauna associada aos bancos de $P$. caudata na Flórida; nesta assembléia, 24 espécies de decápodos perfazem $97 \%$ do número total de indivíduos coletados. No presente estudo, também, verificou-se que os crustáceos constituem o grupo dominante da macrofauna, dos quais os decápodos têm maior riqueza de espécies, embora, não dominantes numericamente. Estes dados permitem inferir que habitats de complexidades semelhantes (recifes de corais e bancos de poliquetos) abrigam macrofauna de composição similar.

Segundo ABELE (1974), sobreviver em um determinado ambiente requer adaptações morfológicas ou fisiológicas, sendo estas mais evidentes nas espécies mais numerosas. PINHEIRO et al. (1997) sugerem que a maior abundância de porcelanídeos nos bancos de $P$. caudata deve-se ao seu hábito alimentar filtrador, ocupando o mesmo nível trófico do poliqueto, alimentando-se de organismos planctônicos e de matéria orgânica em suspensão. Mais tarde, MiCHELETTI-FLORES \& NEGREIROS-FRANSOZO (1999) estudaram a fauna de porcelanídeos associados aos bancos de P. caudata na Praia de Paranapuã, São Paulo e registraram cinco espécies, das quais Pachycheles laevidactylus e Petrolisthes armatus foram as mais numerosas ao longo do período estudado e, foram consideradas constantes em todos os locais amostrados. Estes registros, juntamente com o do presente estudo, permitem confirmar a hipótese de PINHEIRO et al. (1997).

Contrastando-se com os dados de PINHEIRO et al. (1997) que consideram Eriphia gonagra uma espécie constante, neste estudo ela foi acidental. Também, Menippe nodifrons é considerada acidental pelos referidos autores, ao passo que, na Praia de Caiobá, é constante. Eurypanopeus abbreviatus, acessória na Praia Grande, São Paulo, foi constante no presente estudo. Pachygrapsus transversus foi considerada constante em ambas as localidades. Petrolisthes armatus não foi registrado no estudo de Praia Grande, mas duas outras espécies da mesma família foram encontradas, Pachycheles laevidactylus Ortmann, 1893 e Pachycheles monilifer (Dana, 1852), ambas consideradas constantes.

MASUNARI et al. (1998) registraram 27 espécies de decápodos na praia rochosa da Ilha do Farol, Caiobá, das quais seis estão também associadas a $P$. 
caudata da Praia de Caiobá. Naquela praia só não houve Alpheus heterochaelis e Eriphia gonagra. Esta discrepância no número de espécies entre estes dois habitats permite inferir que, uma praia rochosa composta de inúmeros abrigos entre os matacões, cascalhos e pedregulhos, constitui um substrato de maior complexidade estrutural que os bancos de $P$. caudata. Este último substrato parece ser uma alternativa de colonização da assembléia de decápodos. Daí, a maior riqueza de espécies em praias rochosas.

O índice de diversidade obtido (H') para a Praia de Caiobá foi maior do que o da Praia Grande calculado por PINHEIRO et al. (1997) (Tab I.). Tal fato foi devido à menor dominância de Petrolisthes armatus no presente estudo (51,38\%), quando comparada com a Pachycheles laevidactylus no trabalho de Praia Grande (86,04\%); a expressiva dominância desta última espécie promoveu uma redução do índice de diversidade da Praia Grande. Por outro lado, os índices nas quatro localidades estudadas por GORE et al. (1978) são comparativamente maiores, com exceção da localidade de Sebastian, E.U.A.

Tabela I. Comparação dos valores de índice de diversidade de Shannon-Wiener $\left(H^{\prime}\right)$ dos decápodos associados às colônias de Phragmatopoma caudata amostradas em diferentes localidades.

\begin{tabular}{llcccc}
\hline \multirow{2}{*}{ Autor } & \multicolumn{1}{c}{ Local } & \multicolumn{3}{c}{ Número } & \multirow{2}{*}{$\begin{array}{c}H^{\prime} \\
\text { (bits/ind.) }\end{array}$} \\
\cline { 3 - 4 } & & Gêneros & Espécies & Individuos & \\
\hline GORE et al. (1978) & Sebastian, E.U.A. & 5 & 8 & 103 & $1,62 \mathrm{ab}$ \\
& Fort Pierce, E.U.A. & 18 & 31 & 676 & $3,19 \mathrm{c}$ \\
& Walton Rocks, E.U.A. & 17 & 22 & 572 & $2,61 \mathrm{bc}$ \\
& Saint Lucie, E.U.A. & 24 & 37 & 473 & $3,66 \mathrm{c}$ \\
PINHEIRO et al. (1997) & Praia Grande, Ubatuba, SP & 7 & 9 & 1.254 & $0,81 \mathrm{a}$ \\
Presente estudo & Praia de Caiobá, PR & 8 & 8 & 1.769 & $1,99 \mathrm{~b}$ \\
\hline
\end{tabular}

*) Os índices de diversidade seguidos por uma mesma letra não diferiram significativamente $(p>0,05)$.

As diferentes espécies de decápodos tiveram curvas de flutuação de densidade distintas umas das outras corroborando os dados de MASUNARI et al. (1998).

MASUNARI et al. (1998) verificaram que Petrolisthes armatus, Pilumnus dasypodus e Menippe nodifrons apresentam reprodução contínua na Ilha do Farol. No presente estudo, não foi possível definir o período reprodutivo de Menippe nodifrons e de Eriphia gonagra devido ao pequeno tamanho das populações e pela ausência de fêmeas ovígeras e juvenis nas amostragens. PINHEIRO et al. (1997) registraram formas juvenis destas duas espécies em bancos de $P$. caudata de Ubatuba, discordando com o presente estudo.

OliveIRA \& MASUNARI (1995) registraram reprodução contínua de Petrolisthes armatus em substrato rochoso. No presente estudo, a ocorrência descontínua de fêmeas ovígeras ao longo do ano parece estar relacionada com o menor tamanho desta população nos bancos de $P$. caudata.

MASUNARI et al. (1998) encontraram dois períodos principais de reprodução em Panopeus americanus e Eurypanopeus abbreviatus, sempre nos meses com temperatura da água superior ou igual a $20^{\circ} \mathrm{C}$. No presente estudo, Panopeus 
americanus também apresenta dois períodos reprodutivos (Fig. 4). Por outro lado, Eurypanopeus abbreviatus apresentou fêmeas ovígeras somente em dois dos meses amostrados. Ambas as espécies apresentam fêmeas ovígeras nos meses com temperatura da água de superfície superior a $20^{\circ} \mathrm{C}$, corroborando os dados das autoras acima. Pachygrapsus transversus apresentou período reprodutivo de outubro a março na Ilha do Farol (MASUNARI et al. 1998) enquanto, no presente estudo, de setembro a abril. De forma geral, os períodos reprodutivos observados na praia rochosa da Ilha do Farol são mais longos do que aqueles dos bancos de $P$. caudata. A favor desta observação, nenhuma espécie apresentou reprodução contínua nos bancos e nos meses de inverno, fêmeas ovígeras e juvenis não foram registrados. Desta forma, $P$. caudata oferece um substrato distinto da praia rochosa da Ilha do Farol.

A proporção sexual mostra que os machos predominam nas classes de maior tamanho em todas as espécies, fato que é corroborado por OLIVEIRA \& MASUNARI (1995) para Petrolisthes armatus na praia rochosa da Ilha do Farol.

No presente estudo, foi registrado um percentual muito elevado de juvenis nas populações de Petrolisthes armatus e Panopeus americanus, quando comparado com a praia rochosa, o que certamente estaria relacionado com a existência de microhabitats adequados ao assentamento de megalopas nos bancos deste sabelariídeo. Esta inferência tem base no trabalho de KoCH (1982), que demonstrou um recrutamento preferencial de juvenis de várias espécies em locais de maior complexidade topográfica em escala milimétrica. $\mathrm{O}$ sucesso do recrutamento é dependente tanto da morfologia e característica do substrato, mas também da existência de sítios de refúgio (SHULMAN 1984). JOHNSON (1970) considera o recrutamento larval como um dos principais responsáveis pela diversidade das comunidades bentônicas. Uma observação adicional que sustenta tal inferência está no fato das populações de decápodos associadas aos bancos de $P$. caudata serem, na maioria das vezes, de menor porte do que aquelas registradas na literatura (Figs 2 e 7).

GORE et al. (1978) observaram que $90 \%$ dos crustáceos associados a recifes de $P$. caudata da Flórida utilizavam como recurso alimentar o próprio biótopo sabelariídeo. Nesta comunidade, as três principais espécies, Menippe nodifrons (carnívoro bentônico), Pachygrapsus transversus (omnívoro, filtrador) e Panopeus bermudensis (omnívoro, predador facultativo) exploram modos alternativos de obtenção de seu alimento. Esse tipo de utilização diferencial de habitat-alimento, denominado "partilha trófica", talvez seja a chave do sucesso da coexistência de espécies variadas num mesmo habitat.

Embora a riqueza de espécies nos bancos de $P$. caudata da Praia de Caiobá não seja tão elevada quanto nos da Flórida, a "partilha trófica" pode ser um fator importante na composição e manutenção da fauna de decápodos associada. Assim, a coexistência de espécies pode estar relacionada com o modo diferenciado de obtenção de alimento nestes bancos: 1) predador bentônico - Menippe nodifrons; 2) filtrador e ocasionalmente predador - Petrolisthes armatus; 3) omnívoro e ocasionalmente filtrador - Pachygrapsus transversus; e 4) omnívoros e ocasionalmente predadores - Panopeus americanus, Eurypanopeus abbreviatus, Pilumnus dasypodus, Alpheus heterochaelis e Eriphia gonagra. Para os decápodos predado- 


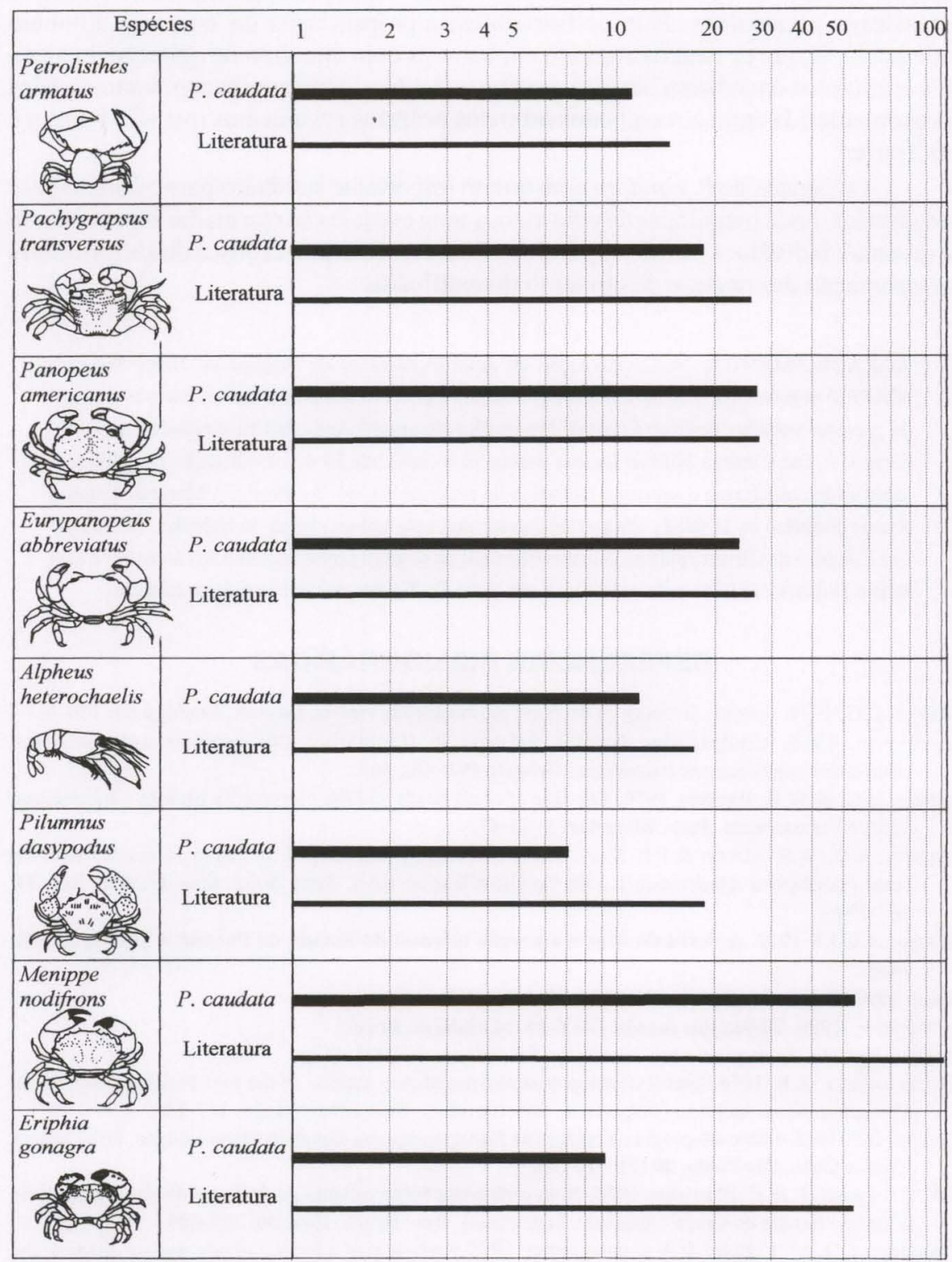

Fig. 7. Amplitude da largura cefalotorácica (LC) ou comprimento cefalotorácico (CC, somente para Alpheus heterochaelis), em milimetros, dos exemplares de decápodos associados aos bancos de Phragmatopoma caudata no presente estudo e daqueles registrados na literatura. Observe que os dados estão em escala logarítmica. 
res, os bancos de $P$. caudata oferecem várias espécies de poliquetos errantes e crustáceos peracáridos. Para os filtradores, a própria água do mar traz alimento adequado, já que os bancos crescem em habitats com alto grau de agitação da água. Os omnívoros encontram detritos orgânicos dentro do próprio banco, tanto aqueles provenientes da água circundante como dos próprios organismos que ali viveram e morreram.

Os bancos de $P$. caudata constituem importante substrato para os crustáceos decápodos, onde megalopas de pelo menos uma espécie são recrutadas intensamente e juvenis e indivíduos de menor porte partilham o substrato na busca de abrigo contra arrebentação das ondas e de alimento diversificado.

\begin{abstract}
AGRADECIMENTOS. À Coordenação de Aperfeiçoamento de Pessoal de Nível Superior (CAPES) pela concessão de uma bolsa de Mestrado à primeira autora durante o desenvolvimento do presente trabalho, junto ao Curso de Pós-graduação em Zoologia da Universidade Federal do Paraná. À Dra Cinthya Simone Gomes Santos pela confirmação de identificação do poliqueto sabelariídeo que forma o substrato biológico do presente estudo. Ao Prof. Dr. Marcelo Antonio Amaro Pinheiro da UNESP, campus de Jaboticabal pela leitura crítica do trabalho. Às amigas Dra Edinalva de Oliveira pelo auxílio nos trabalhos de coleta e processamento das amostras e Dra Janete Dubiaski da Silva pela cobertura a nanquim das figuras dos animais deste trabalho.
\end{abstract}

\title{
REFERÊNCIAS BIBLIOGRÁFICAS
}

ABELE, L.G. 1974. Species diversity of decapod crustaceans in marine habitats. Ecology 55: 156-161. 1976. Comparative species richness in fluctuating and constant environments: coral-associated decapod crustaceans. Science 192: 462-463.

Abele, L.G. \& W.K. Patton. 1976. The size of coral heads and the community biology of associated decapod crustaceans. Jour. Biogeogr. 3: 35-47.

Austin, A.D.; A.S. Austin \& P.F. SALE. 1980. Community structure of the fauna associated with the coral Pocillopora damicornis (L.) on the Great Barrier Reef. Aust. Jour. mar. freshw. Res. 31: 163-174

Bigarella, J.J. 1978. A Serra do Mar e a porção oriental do Estado do Paraná. Curitiba, ADEA, $248 \mathrm{p}$.

DHN. 1997. Tábua das Marés. DG 6-34, Marinha do Brasil.

- 1998. Tábua das marés. DG 6-35, Marinha do Brasil.

DAJOZ, R. 1973. Ecologia Geral. São Paulo, SP, Editora da USP, 472p.

ECKELBARGER, K.E. 1976. Larval development and population aspects of the reef-building polychaete, Phragmatopoma lapidosa (Polychaeta, Sabellariidae). Bull. mar. Sci. 26: 117-132.

FANTA, E.S. 1968. Sôbre a biologia e ecologia de Phragmatopoma lapidosa (Sabellariidae, Polychaeta), Ciên. e Cult., São Paulo, 20 (2): 327-328.

Fausto-Filho, J. \& E. Furtado. 1970. Nota preliminar sôbre a fauna de colônias de Sabellariidae do litoral do Estado do Ceará (Annelida, Sedentaria). Rev. Brasil. Biol. 30: 285-289.

Fenchel, T.; L.M. Kofoed \& A. Lappalaineu. 1975. Particle size selection of two deposit feeders: the amphipod Corophium volutator and the prosobranch Hydrobia ulvae. Mar. Biol. 30: 119-128.

GoRE, R.H.; L.E. SCOTTO \& L.J. BECKER. 1978. Community composition, stability, and trophic partitioning in decapod crustaceans inhabiting some subtropical sabellariid worm reefs. Bull. mar. Sci. 28 (2): 221-248.

Gruet, Y.; J. Vovelle \& M. Grasset. 1987. Composante biominérale du ciment du tube chez Sabellaria alveolata (L.), Annélide Polychète. Can. Jour. Zool. 65 (4): 837-842.

Revta bras. Zool. 19 (Supl. 1): 117 - 133, 2002 
Jensen, R.A. \& D.E. Morse. 1988. The bioadhesive of Phragmatopoma californica tubes: a silk-like cement containing L-DOPA. Fisch. Forsch. 158 (3): 317-324.

JoHnson, R.G. 1970. Variations in diversity within benthic marine communities. Amer. Nat. 104 (937): 285-300.

KREBS, C.J. 1994. Ecology: The experimental analysis of distribution and abundance. New York, Harper Collins College, XIV+801p.

KосH, R.L. 1982. Patterns of abundance variation in reef fishes near an artificial reef at Guam. Environ. Biol. Fish. 7: 121-136.

LitTLER, M.M.; D.R. MARTZ \& D.S. LiTTLER. 1983. The effects of recurrent sand deposition on rocky intertidal organisms: importance of substrate heterogeneity in a fluctuating environment. Mar. Ecol. Progr. Ser. 11 (2): 129-140.

MAACK, R. 1968. Geografia física do Estado do Paraná. Curitiba, Universidade Federal do Paraná, $350 \mathrm{p}$.

MAIN, M.B. \& W.G. NELSON. 1988 a. Tolerance of the sabellariid polychaete Phragmatopoma lapidosa Kinberg to burial, turbidity and hydrogen sulfide. Mar. Environ. Res. 26 (1): 39-55.

MaIN, M.B. \& W.G. NeLSON. 1988 b. Sedimentary characteristics of sabellariid worm reefs (Phragmatopoma lapidosa Kinberg). Estuar. Coast. Shelf Sci. 26 (1): 105-109.

Masunari, S.; E. Oliveira \& V.G.L. Kowalczuck. 1998. Crustacea Decapoda da praia rochosa da Ilha do Farol, Matinhos, Paraná. I. Distribuição temporal de densidade das populações. Revta bras. Zool. 15 (1): 219-239.

Micheletti-Flores, C.V. \& M.L. Negreiros-Fransozo. 1999. Porcellanid crabs (Crustacea, Decapoda) inhabiting sand reefs built by Phragmatopoma lapidosa (Polychaeta, Sabellariidae) at Paranapuã Beach, São Vicente, SP, Brazil. Rev. Brasil. Biol. 59 (1): 59-62.

NARCHI, W. \& S.A. RoDRIGUES. 1965. Observações ecológicas sôbre Phragmatopoma lapidosa Kinberg. Ciên. Cult., São Paulo, 17: 228-229.

Nelson, W.G. \& L. Demetriades. 1992. Peracarids associated with sabellariid worm rock (Phragmatopoma lapidosa Kinberg) at Sebastian Inlet, Florida, USA. Jour. Crust. Biol. 12 (4): 647-654.

OliveIRA, E. \& S. MAsunari. 1995. Estrutura populacional de Petrolisthes armatus (Gibbes) (Decapoda, Anomura, Porcellanidae) da Ilha do Farol, Matinhos, Paraná, Brasil. Revta bras. Zool. 12 (2): 355-371.

PAWLIK, J.R. 1990. Natural and artificial induction of metamorphosis of Phragmatopoma californica (Polychaeta: Sabellariidae), with a critical look at the effects of bioactive compounds on marine invertebrate larvae. Bull. mar. Sci. 46 (2): 512-516.

Pinheiro, M.A.A.; G. Bertini; L.G. Fernandes-Góes \& A. Fransozo. 1997. Decapod crustaceans associated to sand reefs of Phragmatopoma lapidosa Kinberg, 1867 (Polychaeta, Sabellariidae) at Praia Grande, Ubatuba, SP, Brazil. Nauplius 5 (2): 77-83.

Porras, R.; J.V. BATALler; E. Murgui \& M.T. TorRegrosa. 1996. Trophic structure and community composition of polychaetes inhabiting some Sabellaria alveolata (L.) reefs along the Valencia Gulf Coast, Western Mediterranean. Mar. Ecol. 17 (4): 583-602.

SHULMAN, M.J. 1984. Resource limitation and recruitment patterns in a coral reef fish assemblage. Jour. Mar. Biol. Ecol., Amsterdam, 74: 85-109.

TAYLOR, P.R. \& M.M. LiTTLER. 1982. Roles of compensatory mortality, physical disturbance and substrate retention in the development and organization of a sand-influenced, rocky-intertidal community. Ecology 63 (1): 135-146.

Whitlatch, R.B. 1980. Patterns of resource utilizations and coexistence in marine intertidal deposit feeding communities. Jour. mar. Res. 38 (4): 743-765.

WILSON, W.H. 1979. Community structure and species diversity of the sedimentary reefs constructed by Petaloproctus socialis (Polychaeta: Maldanidae). Jour. mar. Res. 37 (4): 623-641.

Recebido em 21.IX.2001; aceito em 06.VI.2002. 